\title{
A study protocol for a clustered randomised controlled trial to evaluate the effectiveness of a peer-led school-based walking intervention on adolescent girls' physical activity: the Walking In ScHools (WISH) study
}

S. Maria O'Kane ${ }^{1 *}$, Angela Carlin ${ }^{1}$, Alison M. Gallagher ${ }^{2}$, lan M. Lahart ${ }^{3}$, Russell Jago ${ }^{4}$, Maria Faulkner ${ }^{5}$ and Marie H. Murphy ${ }^{1}$

\begin{abstract}
Background: Adolescent girls in the UK and Ireland are failing to meet current physical activity guidelines. Physical activity behaviours track from childhood to adulthood and it is important that adolescent girls are provided with opportunities to be physically active. Walking has been a central focus for physical activity promotion in adults and may effectively increase physical activity levels among younger people. Following on from a pilot feasibility trial, the purpose of this cluster randomised controlled trial (c-RCT) is to evaluate the effectiveness of a novel, low-cost, peerled school-based walking intervention delivered across the school year at increasing physical activity levels of adolescent girls.

Methods: The Walking In ScHools (WISH) Study is a school-based c-RCT conducted with girls aged 12-14 years from eighteen schools across the Border Region of Ireland / Northern Ireland. Following baseline data collection, schools will be randomly allocated to intervention or control group. In intervention schools, female pupils aged 15-18 years will be invited to train as walk leaders and will lead younger pupils in 10-15 min walks before school, at break and lunch recess. All walks will take place in school grounds and pupils will be encouraged to participate in as many walks as possible each week. The intervention will be delivered for the whole school year (minimum 20-22 weeks). The primary outcome measure is accelerometer-measured total physical activity (counts per minute) (end of intervention). Secondary outcomes will include time spent in sedentary behaviour, light, moderate and vigorous intensity physical activity, anthropometry measures, social media usage and sleep. A mixed-methods process evaluation will also be undertaken.

(Continued on next page)
\end{abstract}

\footnotetext{
* Correspondence: m.okane@ulster.ac.uk

${ }^{1}$ Centre for Exercise Medicine, Physical Activity and Health, Sports and Exercise Sciences Research Institute, University of Ulster, Jordanstown Campus, Newtownabbey BT37 OQB, UK

Full list of author information is available at the end of the article
}

(c) The Author(s). 2020 Open Access This article is licensed under a Creative Commons Attribution 4.0 International License, which permits use, sharing, adaptation, distribution and reproduction in any medium or format, as long as you give appropriate credit to the original author(s) and the source, provide a link to the Creative Commons licence, and indicate if changes were made. The images or other third party material in this article are included in the article's Creative Commons licence, unless indicated otherwise in a credit line to the material. If material is not included in the article's Creative Commons licence and your intended use is not permitted by statutory regulation or exceeds the permitted use, you will need to obtain permission directly from the copyright holder. To view a copy of this licence, visit http://creativecommons.org/licenses/by/4.0/ The Creative Commons Public Domain Dedication waiver (http://creativecommons.org/publicdomain/zero/1.0/) applies to the data made available in this article, unless otherwise stated in a credit line to the data. 
(Continued from previous page)

Discussion: The WISH Study will examine the effectiveness of a low-cost, school-based, peer-led walking intervention in increasing physical activity in adolescent girls when delivered across the school year. If the intervention increases physical activity, it would benefit adolescent girls in the defined target area with potential for wider adoption by schools across the UK and Ireland.

Trial registration: ISRCTN; ISRCTN12847782; Registered 2nd July 2019.

Keywords: Physical activity, Adolescent girls, Walking, Schools, Intervention

\section{Background}

Regular physical activity is associated with physiological and mental health benefits for adolescents including a reduced risk of obesity, improved fitness and cardiometabolic health, increased muscle and bone strength [1-3]. Despite this, globally, many children fail to meet current guidelines of $60 \mathrm{~min}$ of moderate-to-vigorous physical activity (MVPA) per day [4-6] and it is estimated that on the island of Ireland only $14 \%$ of post-primary school children meet the current recommendations [7]. Physical activity levels decline as children move into adolescence [8] and through to adulthood [7]. This decline is most pronounced among adolescent girls [9] where the average annual reduction in total physical activity from the age of 5 to 18 years is $4.6 \%$ [10]. Importantly, physical activity habits adopted during adolescence track into adulthood $[11,12]$ and may affect the likelihood of developing many chronic health conditions.

Schools are an excellent setting for physical activity promotion among adolescents [13] particularly as children spend $40 \%$ of their waking time at school [14], however, there is a lack of consensus on how best to promote physical activity within the school setting to ensure the maintenance of physical activity behaviours into late adolescence, and adulthood [13]. School-based Physical Education (PE) provides an opportunity for young people to participate in structured, regular physical activity [15] but research has shown that girls are offered significantly less PE time than boys [16]. In addition, extra-curricular physical activity within the school environment often reflects the content of the PE curriculum, i.e. team-based, structured sports [17] and girls are less likely to participate in such activities [18]. School recess may provide an opportunity to promote physical activity. Interventions during recess are feasible $[19,20]$ and female pupils tend to socialise with friends during this time but are less active than males so this period may provide a unique opportunity to increase physical activity levels in adolescent females [21-24].

Walking is the most natural form of physical activity [25] and has been recommended for the promotion of public health [26, 27]. Walking addresses many of the reported barriers to physical activity, such as lack of time, money or poor health [28] and is the most popular form of physical activity for adult women with over 50\% walking for recreation each week [29]. A recent metaanalysis has demonstrated the beneficial effects of walking interventions on adult health [30], however less is understood about the potential of walking to promote physical activity in adolescents. The results of a recent systematic review outlined that walking interventions may provide an effective means for increasing walking in younger populations, at least in the short term but called for additional research into walking and physical activity in adolescents [31]. There is also evidence that walking has benefits for mental health, wellbeing and sleep quality $[32,33]$ but the evidence in the adolescent population is limited.

It is recognised that there are many barriers to participation in physical activity among adolescent girls including a perceived lack of time, peer pressure, negative school experiences, social media and lack of confidence [34-36]. Focus group discussions with adolescent girls have highlighted the characteristics of a school-based intervention acceptable to pupils to encourage participation among low active girls [37]. This work suggested activities that required no change of uniform and could be performed with friends, during the school day, were likely to be accepted and encourage participation [37]. It is recognised that enjoyment of physical activity is positively correlated with physical activity participation levels for adolescents [38] and research has shown that lowactive girls enjoy non-competitive physical activity within the school setting and enjoy physical activity when participating with friends [39]. Research has shown that friends engage in similar levels of physical activity and physical activity interventions within the peer group may be effective as friendship can influences physical activity behaviour [40]. Furthermore, peer leadership is a promising strategy for influencing adolescent behaviour and increasing physical activity as peer leaders can motivate pupils to initiate and sustain behaviour change [41, 42].

Declining physical activity levels during adolescence may be attributable to various other factors including intrapersonal (e.g., self-efficacy, perceived competence, self-image), social (e.g., peer influence) and environmental factors (e.g., gender-relevant physical activity 
opportunities) [43]. It appears that during adolescence there is a lack of interest in the activities offered [44], girls are less likely to engage in organised sport [45] and there is a need to provide physical activity opportunities for those discouraged by the competitive selection process [46] which may increase physical activity in adolescent girls [44, 47]. Considering there is growing pressure on schools to improve academic standards and performance, there is a need for physical activity interventions to be delivered at school but outside of curriculum time [48] and in recent years, there has been growing interest in the promotion of physical activity during school recess [49]. As girls are less active during recess $[22,23,49]$, this period may present an opportunity to promote physical activity. However, despite the potential of school recess to promote physical activity, there is a lack of intervention research in adolescent girls [19] and given the imperative to increase physical activity in adolescent girls, finding effective, sustainable, lowcost interventions is essential.

The aim of this cluster-randomised controlled trial is to evaluate the effectiveness of a novel, low-cost, peerled school-based walking intervention, delivered across the school year, at increasing accelerometer-measured physical activity levels of adolescent girls. It is hypothesised that intervention pupils will increase daily physical activity and replace sedentary behaviour during the school day with walking.

\section{Methods}

\section{Study design}

The WISH study is a school-based clustered randomised controlled trial (c-RCT). The design of the project was informed by a feasibility pilot study [50] that used the Medical Research Council (MRC) [51] framework for complex interventions to develop a peer-led walking intervention. Specifically, following a systematic review of walking interventions in children and adolescents [31], focus groups were conducted to explore the attitudes of adolescents towards physical activity [37]. The findings of both the systematic review and focus groups were used to inform the design of the peer-led, schoolbased walking intervention [50] based on the socioecological framework and informed by Self-Determination Theory (SDT), which provides a framework for understanding and enhancing the motivational mediators of behaviour change [52-54].

Eighteen post-primary schools will be recruited across the Border Region of Ireland / Northern Ireland. Following completion of baseline data collection, schools will be randomised using a 1:1 allocation. Study outcomes will be assessed at four timepoints: baseline (T0), midintervention (T1), end of intervention (T2) and follow up (T3) as outlined in Fig. 1. A mixed-methods process evaluation will be undertaken at baseline and at the end of the intervention. Table 1 provides an overview of data collection and outcome measures, the details of which are provided below.

\section{Recruitment \\ School recruitment}

The study setting will be post-primary schools in the Border Region of Ireland / Northern Ireland. Using school enrolment data [68, 69], schools that meet the following criteria will be invited to participate:

- Northern Ireland: Schools that have at least 80 girls across years 9-10 and located in Co. Derry/ Londonderry

- Ireland: Schools in Co. Donegal with an enrolment of $>240$ girls

Invitation letters accompanied with an expression of interest form will be sent to school principals. Where requested, a member of the research team will visit the school to provide a short overview of the trial for relevant staff. We aim to recruit 18 schools, of which 9 will be randomly allocated to intervention arm with the other 9 allocated to the control arm. Within each school, at least 24 children will be recruited (i.e., minimum of 432 children in total). Should it not be possible to recruit eighteen schools in the selected counties, schools that meet the inclusion criteria (Northern Ireland: at least 80 girls across years 9-10; Ireland: enrolment of > 240 girls) from other counties across the Border Region of Ireland / Northern Ireland will be invited to participate.

\section{Participant recruitment}

Following permission from the school principal, female pupils in Year 9/10 (Northern Ireland) and 1st/2nd year (Ireland) will be invited to take part in the study via a presentation from the study team which will inform $\mathrm{pu}$ pils about the study, the randomisation process and intervention. In schools with $<70$ female pupils in either Year 9/10 (Northern Ireland) or 1st/2nd year (Ireland), all girls in that cohort will be invited to participate. For the larger schools ( $>70$ pupils in either Year 9/10 (Northern Ireland) or 1st/2nd year (Ireland)), each school will be asked to provide a list of the form classes within Year 9/10 (Northern Ireland) or 1st/2nd year (Ireland) and for those schools with mixed ability form classes, classes will be randomly selected to attend the recruitment presentation. If pupils are grouped into form classes based on academic ability, we will randomly invite equal numbers of classes from each band (for example, top, middle and bottom) to attend the recruitment presentation. At a minimum, all potential pupils 


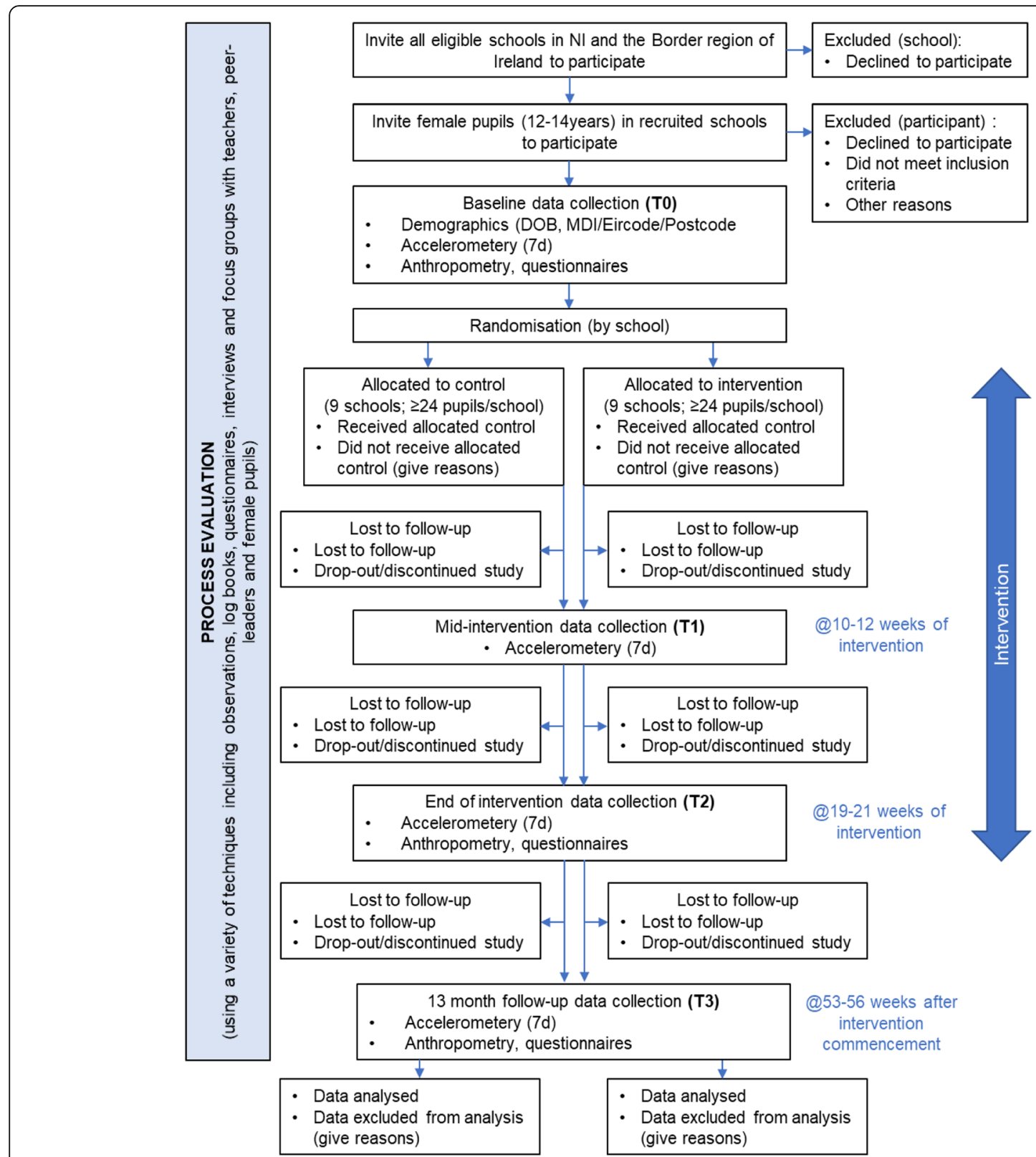

Fig. 1 Study Flow Chart

(and parents/guardians) will be provided with a copy of the participant information sheet. Parents/guardians will be asked to provide written consent. Written assent will be obtained from pupils. The study exclusion criteria are outlined below:

1. Male pupils are not eligible for inclusion in this study, as it seeks to assess the effectiveness of a walking intervention targeted at adolescent girls only.

2. Pupils who are unable to walk or for whom walking is contraindicated will not be eligible for inclusion as taking part in increased physical activity during the school day may not be suitable for this population.

In intervention schools, female pupils aged 15-18 years will be identified by staff and invited to train as walk leaders, lead the walks and participate in an interview at the end of the intervention. One staff contact per intervention school will be recruited for an interview at the end of the intervention and written informed consent will be obtained. Walk leaders will be provided with a participant information sheet and will provide written 
Table 1 WISH Study Data Collection and Outcome Measures

\begin{tabular}{|c|c|c|c|c|}
\hline Outcome measure & Baseline (T0) & Mid-intervention (T1) & $\begin{array}{l}\text { End of } \\
\text { intervention (T2) }\end{array}$ & $\begin{array}{l}\text { 13-month } \\
\text { follow-up (T3) }\end{array}$ \\
\hline Demographic information (age, postcode/Eircode) & $x$ & & & \\
\hline Total physical activity (accelerometery) & $x$ & $x$ & $x$ & $x$ \\
\hline $\begin{array}{l}\text { Time spent in sedentary behaviour, and low, moderate } \\
\text { and vigorous intensity physical activity (accelerometery) }\end{array}$ & $x$ & $x$ & $x$ & $x$ \\
\hline $\begin{array}{l}\text { Proportion of pupils meeting current physical activity } \\
\text { recommendations (accelerometery) }\end{array}$ & $x$ & $x$ & $x$ & $x$ \\
\hline BMI z-scores (height and weight) & $x$ & & $x$ & $x$ \\
\hline Waist: hip ratio (waist and hip circumference) & $x$ & & $x$ & $x$ \\
\hline $\begin{array}{l}\text { Coping, resilience and cognitive reappraisal (Emotion } \\
\text { Regulation Questionnaire for Children) [55] }\end{array}$ & $x$ & & $x$ & $x$ \\
\hline $\begin{array}{l}\text { Sleep quality, duration and efficiency (Pittsburgh Sleep } \\
\text { Quality Index) [56] }\end{array}$ & $x$ & & $x$ & $x$ \\
\hline $\begin{array}{l}\text { Social media use, social integration and emotional } \\
\text { connection to social media }[57,58]\end{array}$ & $x$ & & $x$ & $x$ \\
\hline Body weight and appearance satisfaction [59] & $x$ & & $x$ & $x$ \\
\hline Self-efficacy for physical activity and walking [60] & $x$ & & $x$ & $x$ \\
\hline Health-related quality of life (Kidscreen-10) [61] & $x$ & & $x$ & $x$ \\
\hline Reasons for engaging in physical activity (BREQ-3) $[62,63]$ & $x$ & & $x$ & $x$ \\
\hline Friendship nominations & $x$ & & $x$ & \\
\hline $\begin{array}{l}\text { Process evaluation: focus groups with all pupils } \\
\text { (control \& intervention) }\end{array}$ & $x$ & & & \\
\hline Process evaluation: focus groups with intervention pupils & & & $x$ & \\
\hline $\begin{array}{l}\text { Process evaluation: walk leaders - perception of physical } \\
\text { activity and fitness [64], physical activity self-efficacy [65], physical } \\
\text { activity enjoyment [66] and leadership skills [67] }\end{array}$ & $x$ & & $x$ & \\
\hline Process evaluation: interviews with walk leaders & & & $x$ & \\
\hline Process evaluation: interviews with teachers & & & $x$ & \\
\hline
\end{tabular}

Abbreviations: BMI Body Mass Index

informed consent. Participants will be free to withdraw from the study at any point without giving reason. This study was approved by Ulster University Research Ethics Committee (Ref: REC/19/0020) on 21.06.2019.

\section{Sample size calculations}

Sample size calculations are based on the WISH feasibility trial [50], which detected a mean difference of $11.41 \mathrm{~min}$ in total physical activity (light, moderate and vigorous intensity physical activity) measured using accelerometery between the intervention (2 schools consisting of a total of 79 children) and control (4 schools consisting of 84 children in total) groups. In order to detect a difference of $11.41 \mathrm{~min}$ total physical activity per day between groups, assuming a standard deviation (SD) (pooled intervention and control group SD) of $25 \mathrm{~min}$ in total physical activity, a power of $80 \%$, a significance of 0.05 , an average cluster size of 20 children, an intra-class correlation of 0.03 (calculated from pilot data [50]), and a coefficient of variation of 0.46 , the sample size needed is 15 schools increasing to 16 schools (8 per study arm) to allow for $10 \%$ cluster attrition. To allow for $20 \%$ loss to follow up we will recruit at least 24 children per cluster (at least 384 children in total). Based on recruitment rates of $34 \%$ in our feasibility study [50], all schools that have at least 80 girls across years 9-10 (Northern Ireland) or total enrolment of $>240$ girls (Ireland) will be eligible to participate in the study. From the Northern Ireland School Census [68] we estimate that 77 schools meet these criteria and based on 2016 school recruitment data for Ireland [69] 54 post-primary schools meet these criteria.

\section{Randomisation}

After data collection, schools will be randomly allocated to control $(n=9)$ or intervention $(n=9)$. Randomisation will be stratified by country and random allocation will be performed by faculty staff who will be blind to school identity and independent of the study team. 


\section{Intervention}

Female pupils aged $15-18$ years (peer role models) with few existing extra-curricular commitments within school will be identified by school staff and invited to train as walk leaders to lead younger pupils (aged 12-14 years) in 10-15-min walks before school and at break and lunch recess (maximum 15 walks per week (3 per day)). All walks will occur in school grounds and pupils will be encouraged to participate in many walks as possible each week. Walks will primarily take place outdoors but in adverse weather conditions, indoor routes will be used where possible. Each pupil will be issued with a reward card which will be stamped after each completed walk. These cards will allow pupils to self-monitor their attendance, and stamps can be exchanged for small rewards with low monetary value $(<€ 1)$, for example, pens, pencils, rulers.

The training for walk leaders has been developed in consultation with the Physical Activity Co-Ordinator (Western Health and Social Care Trust) and is based on the Walking For Health Training (Public Health Agency \& NI Health and Social Care Trusts). The training aims to provide an overview of the WISH Study, an understanding of health walks, the expectations of WISH Walk Leaders, knowledge of how to plan walks and keep walkers motivated. The training will also inform walk leaders of the support available for them in this role. Training will be delivered by the Trial Manager on school premises and will last approximately $3 \mathrm{~h}$. The training session has been divided into five sections: 1) completion of consent forms and study questionnaires; 2) ice breakers; 3 ) presentation and group work to focus on ensuring walk leaders consider safety concerns of facilitating the walks and the importance of the walks being performed at a brisk pace, i.e. at a pace sufficient to elicit moderate intensity physical activity in pupils. Training will also include information on providing and encouraging social support amongst pupils to align with SDT; 4) Walk leaders will be provided with instructions on how to plan walk routes (agreed by teachers) and they will also draft the walking timetable and arrange a central meeting point; 5) Walk leaders will have the opportunity to practice leading a walk under the supervision of the Trial Manager. All walk leaders and will be provided with a training manual and asked to evaluate the training programme. Refresher training will be available throughout the intervention. Should a school arrange refresher training, this will last approximately $1 \mathrm{~h}$ and focus on the pace of the walk, encouraging social support and planning new/alternative walking routes. During the refresher training, walk leaders will have the opportunity to practice leading a walk and they will be provided with feedback on pace, route and social engagement. The walk leader training is theoretically underpinned by SDT and similar to the Bristol Girls Dance Project [70], the training facilitator will adopt an autonomy-supportive teaching style that strengthens walk leaders' personal resources. Walk leaders will be encouraged to decide the format of the walks for example, the use of music or games and routes taken. They can also choose to introduce themed walks (for example, Santa walks at Christmas). Walk leaders will be able to self-select the walks that they would like to lead, and the timetable will be determined based on the preferences of the walk leaders. Within a supportive training environment, walk leaders will be provided with the skills and competence to run the walking programme within their school.

Two walk leaders will accompany each walk, one at the front and one at the back of the group. If possible, a third walk leader will be present in the middle of the group. Walk leaders will encourage the younger pupils, set the pace of the walk and ensure the safety of pupils. Walk leaders will be provided with wrist worn heart rate monitors (Mi Band 3, Xiaomi, China) to guide the pace of the walk. Walk leaders will be advised to check that their heart rate is $>135 \mathrm{bpm}$ which indicates that they are walking at a brisk pace [71]. Walk leaders will also be trained to look out for other signs that they are walking at a brisk pace (breathing a little faster; feeling a little warmer; feel their heart beating a little faster; still able to hold a conversation) should they choose not to wear the heart rate monitor. The walk leaders will monitor the pace of the walk and regularly remind pupils that they should be walking at a brisk pace and although there will be variations in fitness and perceived effort, this is reflective of a walking group. For most pupils, walking at the same pace as the walk leaders will be of moderate intensity. Walks will take place in a one of the preplanned routes around the school grounds. At the end of each walk, walk leaders will stamp each pupils reward card and note attendees to monitor compliance with the intervention. Pupils who are not enrolled in the study are permitted to join the walks and will be provided with a reward card which they can exchange for small value rewards. Risk assessments will be performed by a member of the research team and a member of school staff for each predetermined walking route.

Following baseline measurements, the intervention will be delivered for the whole school year. Allowing for holidays, exams, educational trips and other school events this may vary across schools however the intervention will be a minimum 20 and a maximum of 22 weeks. As part of the social support component of the intervention, walk leaders will be invited to be part of a separate closed social media (Facebook) group designed to include opportunities for social support in the form of sharing progress and useful information. In addition, 
social support and encouragement to continue will be provided to walk leaders via weekly updates from the research team which will include: strategies to address barriers to participation, recognising progress; links to websites and resources; and vignettes of support and advice from other walk leaders. These pages will only be accessible to those in the intervention and will be moderated by named members of the research team for data protection.

\section{Outcomes}

\section{Primary outcome}

The primary outcome will be total physical activity (counts per minute) of pupils at the end of the intervention (T2) measured using the Actigraph GT3X accelerometer (Actigraph LLC, Florida) worn for 7 days. The device will be placed on an elastic waist band and pupils will be asked to wear the accelerometer at all times, removing it only for bathing, water-based activities such as swimming and when asleep. Pupils will be asked to wear the accelerometer on their right hip and to ensure that it is worn in the same position each day. Pupils will be asked to wear the accelerometer for seven consecutive days and will be included in the analysis if they have $\geq 2$ valid weekdays of data (500 mins/day) [72]. During measurement periods, pupils will be asked to keep a log of when they wore the accelerometer and took it off to encourage compliance with the wear-time protocol as recommended by Trost et al, 2005 [73]. Minutes of total physical activity (light, moderate and vigorous) per day will be estimated using the Evenson cut-points [74]. A sampling epoch of $15 \mathrm{~s}$ will be employed during data collection. Periods of $\geq 60 \mathrm{~min}$ of zero counts will be categorised as 'non-wear' and removed.

\section{Secondary outcomes}

As outlined in Table 1, a number of secondary outcomes will also be assessed. It is also important to note, however, that there are no statistical power calculations for these assessments and as such all analyses will be presented with point estimates and $95 \%$ confidence intervals but without $p$-values. Accelerometer data will be used to calculate:

- Total physical activity (counts per minute) at midintervention (T1) and follow up (T3)

- Time spent in sedentary behaviour and light, moderate and vigorous intensity physical activity [74] at mid-intervention (T1), end of intervention (T2) and follow up (T3)

- Proportion of pupils meeting current physical activity recommendations [6] at mid-intervention (T1), end of intervention (T2) and follow up (T3)
The following secondary outcomes will be measured at baseline (T0), end of intervention (T2) and follow up (T3) to assess between group differences and changes over time:

- Height $(\mathrm{cm})$ and weight $(\mathrm{kg})$ will be measured to the nearest $0.1 \mathrm{~cm}$ and $0.1 \mathrm{~kg}$, respectively, using a freestanding stadiometer (Leicester Height Measure), and digital scales (Seca 877) to calculate body Mass Index (BMI). BMI will be converted to an age-specific and gender-specific z-score $[75,76]$

- Waist and hip circumference will be measured to the nearest $0.1 \mathrm{~cm}$ using an anatomical measuring tape and waist-to-hip ratio will be calculated.

- Coping, resilience and cognitive reappraisal [55]

- Sleep quality, duration and efficiency (The Pittsburgh Sleep Quality Index) [56]

- Social media use, social integration and emotional connection to social media $[57,58]$

- Body weight and appearance satisfaction [59]

At baseline (T0) the following descriptive data will be collected:

- Date of birth

- Home postcode/Eircode to derive Index of Multiple Deprivation (IMD)

\section{Process evaluation}

A mixed-methods process evaluation will be undertaken. At baseline (T0), end of the intervention (T2) and follow up (T3), pupils (aged 12-14 years) will be asked to complete a series of validated questionnaires to assess self-efficacy for physical activity and walking [60], health-related quality of life [61], reasons for engaging in physical activity $[62,63]$. Friendship nominations will be assessed at baseline (T0) and at the end of the intervention (T2) to determine the effect of social networks on physical activity behaviour and intervention engagement. This will involve each pupil nominating school friends who are also participants in the current study. The number of friends to nominate will not be specified, although 10 lines will be provided on the form. Friendship networks will be constructed from these nominations [77].

At baseline (T0), focus groups will be conducted in all schools and pupils will be randomly invited to participate. The aim of these focus groups is to investigate pupils' motivation for physical activity, barriers to physical activity and the influence of social media usage on their physical activity. At the end of the intervention (T2), high and low attendees from the intervention schools will be invited to take part in focus group discussions. These focus group sessions will enable pupils to share their experience of the WISH trial and assess any 
changes in behaviour pre- and post-intervention. The focus groups will also seek to identify factors that affected participation, motivation and enjoyment of the intervention.

The fidelity of each walk will be assessed through a self-report checklist completed by walk leaders. This will note attendees and assess walk duration and location (indoor/outdoor). To assess how elements of the environment may have affected delivery of the intervention interviews will be conducted with walk leaders. These interviews will be conducted at the end of the intervention (T2). Walk leaders will be asked to complete a brief set of questionnaires at baseline (T0) and end of the intervention (T2) to assess self-perception of physical activity and fitness [64], physical activity self-efficacy [65], physical activity enjoyment [66] and leadership skills [67] to profile the characteristics of those pupils who volunteer as walk leaders.

In addition, an in-depth interview will be held with one school contact (e.g. Head of Key Stage 3 / Head of Year or equivalent) per intervention school at the end of the intervention (T2) to identify key elements that might have affected implementation. Any adverse events will be recorded and reported to the Chair of the Trial Steering Committee and the Chair of the Ethics Committee.

\section{Data analysis}

Data will be entered electronically on a secure file storage system and password protected. Data will be anonymised by assigning a unique identification number to each pupil.

\section{Quantitative analysis}

Outcome data will be reported in accordance with Consolidated Standards of Reporting Trials (CONSORT) guidelines [78]. The statistician performing the data analyses (IML) will be blinded to allocation throughout the study and statistical analysis will only be undertaken when all data has been collected (T3). Pupils will be included in the analysis regardless of compliance with the physical activity intervention. We will apply a multilevel statistical model using ML- win [79] to assess changes in total physical activity (mins per week) from baseline to post-intervention. Multilevel modelling will also be used for the change in total physical activity at other timepoints and secondary continuous outcomes adjusting the false discovery rate using the Benjamini-Hochberg Procedure [80]. Outcomes will be compared between the control and intervention groups using a 2-level multilevel model, with pupils nested within schools. The models will be adjusted for the child-level covariates (level 1): baseline total physical activity (minutes per week), age and BMI z-score; and the following schoollevel covariates (level 2): social economic status
(postcode/Eircode). In the interests of parsimony, covariates will only be retained if their inclusion results in a significant improvement in fit statistics.

\section{Qualitative analysis}

Semi-structured interviews and focus groups will be audio-recorded, transcribed verbatim and anonymised before being coded. Thematic analysis techniques will be used to generate initial codes using NVivo [version 12] and these will be grouped to form themes for each cohort.

\section{Participant remuneration}

All participating schools will be eligible to claim reimbursement for the use of their facilities and for teacher time (up to a maximum total of $€ 400$ ) and provided with a summary of project findings. At each time point, pupils will be provided with an incentive (earphones; water bottle; charger pack or sports top) when they have returned the accelerometer having worn it for a minimum of 2 days ( $€ 17$ total cost). Pupils in the intervention group who take part in ten walks will be able to exchange their reward card for a small value incentive $(<€ 1)$, for example, pen, pencil, ruler.

\section{Patient and public involvement}

The views of low-active adolescents were instrumental in designing the WISH intervention [37, 50, 81]. In advance of the feasibility/pilot, 64 low-active adolescents were consulted on how best to encourage them to increase daily physical activity [37]. The findings informed the development of the school-based, peer-led walking intervention [50]. Following feasibility/pilot, 45 participants provided feedback on both intervention and research components [81]. On the basis of the pilot study, post-primary schools in Northern Ireland $(n=208)$ were surveyed to assess acceptability of a school-based walking intervention [81]. For the current study, Youth Advisory Group (YAG) meetings will be held on four occasions throughout the course of the study (Phase 1: June 2019; Phase 2: March 2020; Post-intervention: June 2021; End of Study: February 2022). Schools from both jurisdictions will be asked to invite pupils aged 12-14 years (participants) and 15-18 years (walk leaders) to the meetings. The YAG will be consulted on all aspects of the research, inform the delivery of the intervention and provide researchers with an understanding of what would encourage/discourage participation. The YAG will advise on resources for pupils and be actively engaged in the dissemination of the findings. In addition, the walk leader training has been developed in consultation with the Physical Activity Co-ordinator (Western Health and Social Care Trust). 


\section{Dissemination of project findings}

In order to disseminate the findings of the study we will hold two dissemination events, one in Northern Ireland and one in Ireland. These will be open to all stakeholders and will present the findings of the research and provide further information on how schools could implement the programme. In addition, all materials used in the intervention will be made available to control schools and to both Education Authorities for dissemination to all schools in the Border Region of Northern Ireland / Ireland. Peer-reviewed publications will allow the results to be disseminated to the scientific community and policy makers. All papers will be submitted for publication in open access journals.

\section{Discussion}

To our knowledge, this is the first fully powered trial that will investigate the effectiveness of a peer-led brisk walking intervention in adolescent girls. The current study builds on a promising pilot trial [50] which confirmed the feasibility of our planned intervention. Patient and public engagement has been and will continue to be central to this study which enhances the acceptability of the intervention, ensures that research is relevant and increases the self-esteem of those staff involved in the project [82].

The WISH Study aims to address several gaps in the current scientific evidence for walking interventions in adolescents. Firstly, until now there have been a limited number of studies which investigate the longer-term effectiveness of physical activity interventions, particularly in children and adolescents [31]. The current study includes longer-term follow up and will measure physical activity at 13 months' post-intervention to address the paucity of evidence on the longer-term effectiveness of physical activity interventions in children and adolescents. Secondly, the WISH Study aims to provide adolescent girls with extra opportunities to be active at break and lunchtime and given the limited number of structured walking recess-based interventions [31], this study will address this specific gap in the current evidence base. In terms of study methodology, it is estimated that there are more than twelve methods available for measuring physical activity [83] and although there is no universally agreed "gold standard" method [84-86] the use of accelerometers enables us to objectively measure physical activity and provide information on the intensity, duration and frequency of physical activity $[85,87]$.

In accordance with MRC guidelines [88], the research team will undertake an in-depth mixed method process evaluation and the perspectives of multiple stakeholders (i.e. pupils, walk leaders and teachers) will be sought. This will enable a robust evaluation of how the intervention was implemented and an accurate interpretation of either positive and/or negative outcomes $[89,90]$.

To conclude, if the WISH intervention increases physical activity, there is potential for the programme to be widely implemented by schools resulting in a sustainable, long-term, positive impact on adolescent population health.

\section{Abbreviations \\ CONSORT: Consolidated Standards of Reporting Trials; C-RCT: Clustered Randomised Controlled Trial; BMI: Body Mass Index; IMD: Index of Multiple Deprivation; MRC: Medical Research Council; MVPA: Moderate-to-vigorous physical activity; NICHE: Nutrition Innovation Centre for Food and Health; PE: Physical Education; SD: Standard Deviation; SDT: Self-Determination Theory; WISH: Walking In ScHools; YAG: Youth Advisory Group}

\section{Acknowledgements}

This study has been supported by the Health and Social Care (HSC) Research \& Development Division Cross-border Healthcare Intervention Trials in Ireland Network (CHITIN) programme, funded by the European Union's INTERREG VA Programme, managed by the Special EU Programmes Body (SEUPB).

\section{Authors' contributions}

The study design and concept were conceived by AC, MHM and AMG. AC conducted the feasibility study as part of her PhD under the supervision of MHM and AMG. RJ designed the process evaluation and IML wrote the statistical analysis plan and conducted the sample size calculation. SMO'K prepared the first draft of the manuscript and MF advised on issues relating to the conduct of research, school recruitment and interoperability in Ireland. All authors provided edits and critiqued the manuscript for scientific content. All authors read and approved the final version of the manuscript.

\section{Funding}

The WISH Study is funded from INTERREG VA funding of $€ 8.84 \mathrm{~m}$ (incl. 15\% contribution from the Department of Health in Northern Ireland and Republic of Ireland) that had been awarded to the HSC Research \& Development Division of the Public Health Agency Northern Ireland and to the Health Research Board in Ireland for the Cross-border Healthcare Intervention Trials in Ireland Network (CHITIN) project. The funders had no role in the design of this study and will not have any role during its execution, analyses, interpretation of the data, or decision to submit results.

The sponsor of this study is Ulster University, Shore Road, Newtownabbey, Co. Antrim, BT37 OQB. The study sponsor was not involved in study design.

Availability of data and materials

Not applicable at this point.

\section{Ethics approval and consent to participate}

Ethical approval for the study was obtained from the Ulster University Research Ethics Committee and the trial is registered with ISRCTN, protocol number ISRCTN 12847782. Parent/Guardians will be asked to provide written informed consent. Written assent will also be obtained from pupils prior to commencing the study.

Consent for publication

Not applicable.

\section{Competing interests}

The authors declare that they have no competing interests.

\section{Author details}

${ }^{1}$ Centre for Exercise Medicine, Physical Activity and Health, Sports and Exercise Sciences Research Institute, University of Ulster, Jordanstown Campus, Newtownabbey BT37 0QB, UK. ${ }^{2}$ Nutrition Innovation Centre for Food and Health (NICHE), Biomedical Sciences Research Institute, University of Ulster, Coleraine Campus, Coleraine BT52 1SA, UK. ${ }^{3}$ Faculty of Education, Health and Wellbeing, University of Wolverhampton, Walsall Campus, Gorway Road, Walsall WS1 3BD, UK. ${ }^{4}$ Centre for Exercise, Nutrition \& Health 
Sciences, School for Policy Studies, University of Bristol, Bristol BS8 1TZ, UK. ${ }^{5}$ Department of Law and Humanities, Letterkenny Institute of Technology, Port Road, Letterkenny, Ireland.

Received: 29 October 2019 Accepted: 26 March 2020

Published online: 21 April 2020

\section{References}

1. Biddle SJH, Asare M. Physical activity and mental health in children and adolescents: a review of reviews. Br J Sports Med. 2011;45:886-95. https:// doi.org/10.1136/bjsports-2011-090185.

2. Janssen I, LeBlanc AG. Systematic review of the health benefits of physical activity and fitness in school-aged children and youth. Int J Behav Nutr Phys Act. 2010;7:40. https://doi.org/10.1186/1479-5868-7-40.

3. Strong WB, Malina RM, Blimkie CJR, Daniels SR, Dishman RK, Gutin B, et al. Evidence based physical activity for school-age youth. J Pediatr. 2005;146: 732-7. https://doi.org/10.1016/j.jpeds.2005.01.055.

4. Department of Health and Children, Health Service Executive. The national guidelines on physical activity for Ireland. 2009. https://health.gov.ie/wpcontent/uploads/2014/03/active_guidelines.pdf.

5. Haskell W, Bull FC, Andersen LB, Hallal PC, Guthold R, Ekelund U. Global physical activity levels: surveillance progress, pitfalls, and prospects. Lancet. 2012;380:247-57. https://doi.org/10.1016/s0140-6736(12)60646-1.

6. UK Chief Medical Officers. Physical activity guidelines. 2019. https://assets. publishing.service.gov.uk/government/uploads/system/uploads/attachment_ data/file/832868/uk-chief-medical-officers-physical-activity-guidelines.pdf.

7. Harrington DM, Murphy M, Carlin A, Coppinger T, Donnelly A, Dowd KP, et al. Results from Ireland north and South's 2016 report card on physical activity for children and youth. J Phys Act Health. 2016;13:S183-8. https:// doi.org/10.1123/jpah.2016-0334.

8. Allison KR, Adlaf EM, Dwyer JJM, Lysy DC, Irving HM. The decline in physical activity among adolescent students: a cross-national comparison. Can J Public Health. 2007:98:97-100. https://doi.org/10.1007/BF03404317.

9. Metcalf BS, Hosking J, Jeffery AN, Henley WE, Wilkin TJ. Exploring the adolescent fall in physical activity: a 10-yr cohort study. Med Sci Sports Exerc. 2015;47:2084-92. https://doi.org/10.1249/MSS.0000000000000644.

10. Cooper AR, Goodman A, Page AS, Sherar LB, Esliger DW, van Sluijs EMF, et al. Objectively measured physical activity and sedentary time in youth: the International children's accelerometry database (ICAD). Int J Behav Nutr Phys Act. 2015;12:113. https://doi.org/10.1186/s12966-015-0274-5.

11. Telama R. Tracking of physical activity from childhood to adulthood: a review. Obes Facts. 2009:2:187-95. https://doi.org/10.1159/000222244.

12. Hayes G, Dowd KP, MacDonncha C, Donnelly AE. Tracking of physical activity and sedentary behavior from adolescence to Young adulthood: a systematic literature review. J Adolesc Health. 2019. https://doi.org/10.1016/j. jadohealth.2019.03.013

13. Dobbins M, DeCorby K, Robeson P, Husson H, Tirilis D. School-based physical activity programs for promoting physical activity and fitness in children and adolescents aged 6-18. Cochrane Database Syst Rev. 2009. https://doi.org/10.1002/14651858.CD007651.

14. Fox KR, Cooper A, McKenna J. The school and promotion of Children's health-enhancing physical activity: perspectives from the United Kingdom. J Teach Phys Educ. 2016;23:338-58. https://doi.org/10.1123/jtpe.23.4.338.

15. Fairclough S, Stratton G. "Physical education makes you fit and healthy". Physical education's contribution to young people's physical activity levels. Health Educ Res. 2005:20:14-23. https://doi.org/10.1093/her/cyg101.

16. Woods, C.B., Tannehill D., Quinlan, A., Moyna, N., Walsh J. The Children's Sport Participation and Physical Activity Study (CSPPA). Research Report No 1. 2010. https://www.ucd.ie/t4cms/CCLSP_Study_Report1.pdf.

17. Cale L. Physical activity promotion in secondary schools. Eur Phys Educ Rev. 2000;6:71-90. https://doi.org/10.1177/1356336X000061006.

18. Grappendorf $\mathrm{H}$. Where We've been, where we are, where We're going: girls and women in sport and physical activity. Women Sport Phys Act J. 2016; 20:93-4. https://doi.org/10.1123/wspaj.20.1.93.

19. Parrish AM, Okely AD, Stanley RM, Ridgers ND. The effect of school recess interventions on physical activity: a systematic review. Sport Med. 2013;43: 287-99. https://doi.org/10.1007/s40279-013-0024-2

20. Ickes MJ, Erwin H, Beighle A. Systematic review of recess interventions to increase physical activity. J Phys Act Health. 2013;10:910-26. https://doi.org/ 10.1123/jpah.10.6.910.
21. Ridgers ND, Stratton G, Fairclough SJ, Twisk JWR. Children's physical activity levels during school recess: a quasi-experimental intervention study. Int J Behav Nutr Phys Act. 2007:4:19. https://doi.org/10.1186/1479-5868-4-19.

22. Hohepa M, Scragg R, Schofield G, Kolt GS, Schaaf D. Self-reported physical activity levels during a segmented school day in a large multiethnic sample of high school students. J Sci Med Sport. 2009;12:284-92. https://doi.org/10. 1016/j.jsams.2007.11.005.

23. Niven AG, Fawkner SG, Knowles AM, Henretty JM. From primary to secondary school: changes in Scottish girls' physical activity and the influence of maturation and perceptions of competence. Edinburgh; 2009 https://funding4sport.co.uk/downloads/women_changes_scottish_girls.pdf.

24. Baines $E$, Blatchford $P$. Sex differences in the structure and stability of children's playground social networks and their overlap with friendship relations. Br J Dev Psychol. 2009;27:743-60. https://doi.org/10.1348/ $026151008 \times 371114$

25. Morris JN, Hardman AE. Walking to health. Sport Med. 1997;23:306-32. https://doi.org/10.2165/00007256-199723050-00004.

26. de Moor D. Walking Works: Making the case to encourage greater uptake of walking as a physical activity and recognise the value and benefits of Walking for Health. 2013. https://www.walkingforhealth.org.uk/sites/default/ files/Walkingworks_LONG_AW Web.pdf.

27. National Institute for Health \& Care Excellence (NICE). Physical activity: walking and cycling: Public health guideline. 2012. www.nice.org.uk/ guidance/ph41.

28. Townsend, N. Bhatnagar, P. Wickramasinghe, K. Scarborough, P. Foster, C. Rayner M. Physical activity statistics 2012. 2012. https://www.bhf.org.uk/ / media/files/research/heart-statistics/m130-bhf_physical-activitysupplement_2012.pdf.

29. Murphy MH, Donnelly P, Shibli S, Foster C, Nevill AM. Physical activity, walking and leanness: an analysis of the Northern Ireland sport and physical activity survey (SAPAS). Prev Med (Baltim). 2012;54:140-4. https://doi.org/10. 1016/j.ypmed.2011.12.008.

30. Murtagh EM, Nichols L, Mohammed MA, Holder R, Nevill AM, Murphy MH. The effect of walking on risk factors for cardiovascular disease: an updated systematic review and meta-analysis of randomised control trials. Prev Med (Baltim). 2015;72:34-43. https://doi.org/10.1016/j.ypmed.2014.12.041.

31. Carlin A, Murphy MH, Gallagher AM. Do interventions to increase walking work? A systematic review of interventions in children and adolescents. Sports Med. 2016;46:515-30. https://doi.org/10.1007/s40279-015-0432-6.

32. Kelly P, Williamson C, Niven AG, Hunter R, Mutrie N, Richards J. Walking on sunshine: scoping review of the evidence for walking and mental health. $\mathrm{Br}$ J Sports Med. 2018;52:800-6. https://doi.org/10.1136/bjsports-2017-098827.

33. Hori H, Ikenouchi-Sugita A, Yoshimura R, Nakamura J. Does subjective sleep quality improve by a walking intervention? A real-world study in a Japanese workplace. BMJ Open. 2016;6. https://doi.org/10.1136/bmjopen-2016-011055.

34. Allender S, Cowburn G, Foster C. Understanding participation in sport and physical activity among children and adults: a review of qualitative studies. Health Educ Res. 2006;21:826-35. https://doi.org/10.1093/her/cyl063.

35. Wetton AR, Radley $R$, Jones AR, Pearce MS. What are the barriers which discourage 15-16 year-old girls from participating in team sports and how can we overcome them? Biomed Res Int. 2013. https://doi.org/10.1155/ 2013/738705

36. Vaterlaus JM, Patten EV, Roche C, Young JA. Gettinghealthy: the perceived influence of social media on young adult health behaviors. Comput Human Behav. 2015:45:151-7. https://doi.org/10.1016/j.chb.2014.12.013.

37. Carlin A, Murphy MH, Gallagher AM. Current influences and approaches to promote future physical activity in 11-13 year olds: a focus group study. BMC Public Health. 2015;15. https://doi.org/10.1186/s12889-015-2601-9.

38. Dishman RK, Motl RW, Saunders R, Felton G, Ward DS, Dowda M, et al. Enjoyment mediates effects of a school-based physical-activity intervention. Med Sci Sports Exerc. 2005;37:478-87. https://doi.org/10.1249/01.mss. 0000155391.62733.a7.

39. Owen M, Kerner C, Newson L, Noonan R, Curry W, Kosteli M-C, et al. Investigating adolescent girls' perceptions and experiences of school-based physical activity to inform the girls' peer activity intervention study. J Sch Health. 2019;89:730-8. https://doi.org/10.1111/josh.12812.

40. MacDonald-Wallis K, Jago R, Sterne JAC. Social network analysis of childhood and youth physical activity: a systematic review. Am J Prev Med. 2012;43:636-42. https://doi.org/10.1016/j.amepre.2012.08.021.

41. Barr-Anderson DJ, Laska MN, Veblen-Mortenson S, Farbakhsh K, Dudovitz B, Story M. A school-based, peer leadership physical activity intervention for 
6th graders: feasibility and results of a pilot study. J Phys Act Health. 2012;9: 492-9. https://doi.org/10.1123/jpah.9.4.492.

42. Jenkinson KA, Naughton G, Benson AC. The GLAMA (Girls! Lead! Achieve! Mentor! Activate!) physical activity and peer leadership intervention pilot project: a process evaluation using the RE-AIM framework. BMC Public Health. 2012;12:55. https://doi.org/10.1186/1471-2458-12-55.

43. Biddle SJH, Gorely T, Stensel DJ. Health-enhancing physical activity and sedentary behaviour in children and adolescents. J Sports Sci. 2004;22:679701. https://doi.org/10.1080/02640410410001712412.

44. Yungblut HE, Schinke RJ, Mcgannon KR. Views of adolescent female youth on physical activity during early adolescence. J Sport Sci Med. 2012;11:3950 https:/www.ncbi.nlm.nih.gov/pmc/articles/PMC3737842/.

45. Vella SA, Cliff DP, Okely AD. Socio-ecological predictors of participation and dropout in organised sports during childhood. Int I Behav Nutr Phys Act. 2014;11. https://doi.org/10.1186/1479-5868-11-62.

46. Humbert ML, Chad KE, Bruner MW, Spink KS, Muhajarine N, Anderson KD, et al. Using a naturalistic ecological approach to examine the factors influencing youth physical activity across grades 7 to 12. Health Educ Behav. 2008;35:158-73. https://doi.org/10.1177/1090198106287451.

47. Whitehead S, Biddle S. Adolescent girls' perceptions of physical activity: a focus group study. Eur Phys Educ Rev. 2008;14:243-62. https://doi.org/10. 1177/1356336X08090708.

48. Sebire SJ, McNeill J, Pool L, Haase AM, Powell J, Jago R. Designing extracurricular dance programs: UK physical education and dance teachers' perspectives. Open J Prev Med. 2013;03:111-7. https://doi.org/10.4236/ojpm. 2013.31014.

49. Ridgers ND, Stratton G, Fairclough SJ. Physical activity levels of children during school playtime. Sports Med. 2006;36:359-71. https://doi.org/10. 2165/00007256-200636040-00005.

50. Carlin A, Murphy MH, Nevill A, Gallagher AM. Effects of a peer-led walking in ScHools intervention (the WISH study) on physical activity levels of adolescent girls: a cluster randomised pilot study. Trials. 2018;19. https://doi. org/10.1186/s13063-017-2415-4.

51. Craig P, Dieppe P, Macintyre S, Michie S, Nazareth I, Petticrew M, et al. Developing and evaluating complex interventions: the new Medical Research Council guidance. BMJ. 2008;337. https://doi.org/10.1136/bmj.a1655.

52. Ryan RM, Deci EL. Self-determination theory. Am Psychol. 2000;55:68-78. https://doi.org/10.1037/0003-066X.55.1.68

53. Standage M, Ryan RM. Self-determination theory and exercise motivation: facilitating self-regulatory processes to support and maintain health and well-being. In: Advances in Motivation in Sport and Exercise. Third ed. Champaign: Human Kinetics; 2012. p. 233-70.

54. Jago R, Edwards MJ, Sebire SJ, Cooper AR, Powell JE, Bird EL, et al. Bristo girls dance project (BGDP): protocol for a cluster randomised controlled trial of an after-school dance programme to increase physical activity among 11-12 year old girls. BMC Public Health. 2013;13. https://doi.org/10.1186/ 1471-2458-13-1003.

55. Gullone E, Taffe J. The emotion regulation questionnaire for children and adolescents (ERQ-CA): a psychometric evaluation. Psychol Assess. 2012;24: 409-17. https://doi.org/10.1037/a0025777.

56. Buysse DJ, Reynolds CF, Monk TH, Berman SR, Kupfer DJ. The Pittsburgh sleep quality index: a new instrument for psychiatric practice and research. Psychiatry Res. 1989;28:193-213. https://doi.org/10.1016/01651781(89)90047-4

57. Woods HC, Scott H. \#Sleepyteens: social media use in adolescence is associated with poor sleep quality, anxiety, depression and low self-esteem. J Adolesc. 2016;51:41-9. https://doi.org/10.1016/j.adolescence.2016.05.008.

58. Jenkins-Guarnieri MA, Wright SL, Johnson B. Development and validation of a social media use integration scale. Psychol Pop Media Cult. 2013;2:38-50. https://doi.org/10.1037/a0030277.

59. Kelly Y, Zilanawala A, Booker C, Sacker A. Social media use and adolescent mental health: findings from the UK millennium cohort study. EClinicalMedicine. 2018;6:59-68. https://doi.org/10.1016/j.eclinm.2018.12.005.

60. Garcia AW, Pender NJ, Antonakos CL, Ronis DL. Changes in physical activity beliefs and behaviors of boys and girls across the transition to junior high school. J Adolesc Health. 1998;22:394-402. https://doi.org/10.1016/S1054139X(97)00259-0.

61. Ravens-Sieberer U, Gosch A, Rajmil L, Erhart M, Bruil J, Duer W, et al. KIDSCREEN-52 quality-of-life measure for children and adolescents. Expert Rev Pharmacoeconomics Outcomes Res. 2005:5:353-64. https://doi.org/10. 1586/14737167.5.3.353.
62. Markland D, Tobin V. A modification to the behavioural regulation in exercise questionnaire to include an assessment of Amotivation. J Sport Exerc Psychol. 2016;26:191-6. https://doi.org/10.1123/jsep.26.2.191.

63. Wilson PM, Rodgers WM, Loitz CC, Scime G. It's who I am ... really!' The importance of integrated regulation in exercise contexts. J Appl Biobehav Res. 2007;11:79-104. https://doi.org/10.1111/j.1751-9861.2006.tb00021.x.

64. Baceviciene M, Jankauskiene R, Emeljanovas A. Self-perception of physical activity and fitness is related to lower psychosomatic health symptoms in adolescents with unhealthy lifestyles. BMC Public Health. 2019;19. https:// doi.org/10.1186/s12889-019-7311-2.

65. Bartholomew JB, Loukas A, Jowers EM, Allua S. Validation of the physical activity self-efficacy scale:testing measurement invariance between Hispanic and Caucasian children. J Phys Act Health. 2006;3:70-8. https://doi.org/10. 1123/jpah.3.1.70.

66. Jambunathan S, Jayaraman JD, Jayaraman K, Jayaraman A. Effect of peer-led leadership workshops on leadership skills among middle school students in India. J Res Child Educ. 2019;33:399-413. https://doi.org/10.1080/02568543. 2019.1608336

67. Motl RW, Dishman RK, Saunders R, Dowda M, Felton G, Pate RR. Measuring enjoyment of physical activity in adolescent girls. Am J Prev Med. 2001;21: 110-7. https://doi.org/10.1016/S0749-3797(01)00326-9.

68. Department of Education. Annual enrolments at schools and in pre-school education in Northern Ireland, 2018/19. 2019. https://www.education-ni.gov. uk/publications/school-enrolments-201819-statistical-bulletins.

69. Department of Education \& Skills. Statistical Bulletin - Enrolments September 2018- Preliminary Results. 2018. https://www.education.ie/en/Publications/ Statistics/Data-on-Individual-Schools/.

70. Jago R, Edwards MJ, Sebire SJ, Bird EL, Tomkinson K, Kesten JM, et al. Bristol girls dance project: a cluster randomised controlled trial of an after-school dance programme to increase physical activity among 11- to 12-year-old girls. Public Heal Res. 2016;4:1-176. https://doi.org/10.3310/phr04060.

71. Tanaka H, Monahan KD, Seals DR. Age-predicted maximal heart rate revisited. J Am Coll Cardiol. 2001;37:153-6. https://doi.org/10.1016/S07351097(00)01054-8.

72. Willis K, Tibbitts B, Sebire SJ, Reid T, MacNeill SJ, Sanderson E, et al. Protocol for a cluster randomised controlled trial of a peer-led physical activity iNtervention for adolescent girls (PLAN-A). BMC Public Health. 2019;19. https://doi.org/10.1186/s12889-019-7012-x.

73. Trost SG, Mciver KL, Pate RR. Conducting accelerometer-based activity assessments in field-based research. Med Sci Sports Exerc. 2005;37:S531-43. https://doi.org/10.1249/01.mss.0000185657.86065.98.

74. Evenson KR, Catellier DJ, Gill K, Ondrak KS, McMurray RG. Calibration of two objective measures of physical activity for children. J Sports Sci. 2008;26: 1557-65. https://doi.org/10.1080/02640410802334196.

75. Cole TJ, Freeman JV, Preece MA. Body mass index reference curves for the UK, 1990. Arch Dis Child. 1995;73:25-9. https://doi.org/10.1136/adc.73.1.25.

76. Cole TJ, Bellizzi MC, Flegal KM, Dietz WH. Obesity Worldwide : International Survey. BMJ. 2000;320(1):1-6. https://doi.org/10.1136/bmj.320.7244.1240.

77. de la Haye K, Robins G, Mohr P, Wilson C. Obesity-related behaviors in adolescent friendship networks. Soc Networks. 2010;32:161-7. https://doi. org/10.1016/j.socnet.2009.09.001.

78. Schulz KF, Altman DG, Moher D, for the CONSORT Group (Consolidated Standards of Reporting Trials). CONSORT 2010 Statement: updated guidelines for reporting parallel group randomised trials. BMC Med. 2010;8: 18. https://doi.org/10.1186/1741-7015-8-18.

79. Goldstein H. Multilevel Statistical Models. London: Edward Arnold; 2003.

80. Benjamini Y, Hochberg Y. Controlling the False Discovery Rate - a Practical and Powerful Approach to Multiple Testing. J R Stat Soc. 1995;57:289-300. https://doi.org/10.2307/2346101.

81. Carlin A, Murphy M, Gallagher A. Using the school environment to promote walking amongst adolescent females: a mixed-method study. Children. 2019;6. https://doi.org/10.3390/children6030049.

82. Sonpal K, Walker E, Swallow V, Brady L-M, Stones S. Report on involving children and young people in research. Southampton; 2019. https://www. invo.org.uk/posttypepublication/report-on-involving-children-and-youngpeople-in-research/.

83. Tudor-Locke CE, Myers AM. Challenges and opportunities for measuring physical activity in sedentary adults. Sports Med. 2001;31:91-100. https://doi. org/10.2165/00007256-200131020-00002.

84. Kelly P, Fitzsimons $C$, Baker $G$. Should we reframe how we think about physical activity and sedentary behaviour measurement? Validity and 
reliability reconsidered. Int J Behav Nutr Phys Act. 2016;13. https:/doi.org/ 10.1186/s12966-016-0351-4.

85. Ridgers ND, Fairclough S. Assessing free-living physical activity using accelerometry: practical issues for researchers and practitioners. Eur J Sport Sci. 2011;11:205-13. https://doi.org/10.1080/17461391.2010.501116.

86. Aparicio-Ugarriza R, Mielgo-Ayuso J, Benito PJ, Pedrero-Chamizo R, Ara I, González-Gross M, et al. Physical activity assessment in the general population; instrumental methods and new technologies. Nutr Hosp. 2015; 31(Suppl 3):219-26. https://doi.org/10.3305/nh.2015.31.sup3.8769.

87. Strath SJ, Kaminsky LA, Ainsworth BE, Ekelund U, Freedson PS, Gary RA, et al. Guide to the assessment of physical activity: clinical and research applications: a scientific statement from the American Heart Association. Circulation. 2013;128:2259-79. https://doi.org/10.1161/01.cir.0000435708. 67487.da.

88. Moore GF, Audrey S, Barker M, Bond L, Bonell C, Hardeman W, et al. Process evaluation of complex interventions: Medical Research Council guidance. BMJ. 2015;350. https://doi.org/10.1136/bmj.h1258.

89. Durlak JA, DuPre EP. Implementation matters: a review of research on the influence of implementation on program outcomes and the factors affecting implementation. Am J Community Psychol. 2008;41:327-50. https://doi.org/10.1007/s10464-008-9165-0.

90. Taylor SL, Noonan RJ, Knowles ZR, Owen MB, Fairclough SJ. Process evaluation of a pilot multi-component physical activity intervention - active schools: Skelmersdale. BMC Public Health. 2018;18. https://doi.org/10.1186/ s12889-018-6272-1.

\section{Publisher's Note}

Springer Nature remains neutral with regard to jurisdictional claims in published maps and institutional affiliations.

Ready to submit your research? Choose BMC and benefit from:

- fast, convenient online submission

- thorough peer review by experienced researchers in your field

- rapid publication on acceptance

- support for research data, including large and complex data types

- gold Open Access which fosters wider collaboration and increased citations

- maximum visibility for your research: over $100 \mathrm{M}$ website views per year

At $\mathrm{BMC}$, research is always in progress.

Learn more biomedcentral.com/submissions 